\title{
Visibilizar, sensibilizar, engajar: atuação de Brokers nos processos de resistência ao pré-sal no estado do Espírito Santo ${ }^{1}$
}

\author{
Julia Silva de Castro
}

\begin{abstract}
Resumo: Partindo das atuais discussões acerca das mobilizações em torno dos impactos de atividades extrativistas na América Latina, busca-se compreender o processo de contestação dos afetados pela indústria do petróleo e gás no estado do Espírito Santo, tendo em vista as intermediações entre o local e o global. Diferentes valorações e práticas estão envolvidas no processo de mobilização e, nesse sentido, o intercâmbio de afetados, enquanto a materialização de uma performance constituída através de um ator "glocal", ou broker, irá forjar uma vivência capaz de vincular demandas locais com enquadramentos que possuam projeção global.
\end{abstract}

Palavras-chave: Neoextrativismo; conflitos ambientais; América Latina; redes de ativismo ambiental; Brokerage.

\section{Visualize, sensitize, engage: brokers' performance in pre-salt resistance processes at Espírito Santo estate, Brazil}

\begin{abstract}
Starting from the prevailing discussions about the mobilizations regarding the impacts from extractivist activities in Latin America, this paper intendeds to grasp the process of contestation of those affected by the oil and gas industry at Espírito Santo estate, in view of the intermediation between local and global. Many different
\end{abstract}

${ }^{1}$ Este trabalho é uma versão do paper originalmente apresentado no GT 11 "Entre ruas e gabinetes" durante o $41^{\circ}$ Encontro Anual da ANPOCS. Recebido em 31/12/17 e aprovado em 31/05/18.

2 Mestranda no Programa de Pós-Graduação em Ciências Sociais pela Universidade Federal do Espírito Santo (PGCS/UFES), bolsista FAPES e Pesquisadora Associada do Núcleo de Estudo, Pesquisa e Extensão em Mobilizações Sociais - Organon/UFES. E-mail: julia.scastro92@gmail.com 
valuations and practices are involved in the process of mobilization and, in this sense, the exchange of affected, while the materialization of a performance constituted through a "glocal" actor, or broker, will forge an experience capable of linking local demands with frameworks that have global projection.

Keywords: Neoextravism; environmental conflicts; Latin America; environmental activism networks; Brokerage.

\section{Visibilizar, sensibilizar, involucrar: actuación de brokers en los procesos de resistencia al pre-sal en el estado del Espírito Santo, Brasil}

Resumen: A partir de las actuales discusiones sobre las movilizaciones acerca de los impactos de actividades extractivas en América Latina, se busca comprender el proceso de contestación de los afectados por la industria del petróleo y gas en el estado de Espírito Santo, teniendo en cuenta las intermediaciones entre el local y global. Diferentes valoraciones y prácticas están involucradas en el proceso de movilización $\mathrm{y}$, en ese sentido, el intercambio de afectados, mientras que la materialización de una performance constituida a través de un actor "glocal", o broker, va a forjar una vivencia capaz de vincular demandas locales con encuadramientos que tengan proyección global.

Palabras clave: Neoextractivismo; conflictos ambientales; América Latina; redes de activismo ambiental; Brokerage.

\section{Introdução}

Em coerência com a lógica contemporânea de expansão e reprodução do capital baseado em uma economia extrativa, o Espírito Santo passou a ocupar, nos últimos anos, certo destaque nos incentivos à instalação de megaempreendimentos ${ }^{3}$. Considera-

3 O documento ES 2025: Plano de Desenvolvimento estabelece uma relação favorável entre a ideia de crescimento econômico e as atividades decorrentes da indústria de commodities, tendo em vista o amplo fomento aos projetos centrados nas indústrias de base (ferro, aço, minérios, celulose, pré-sal) e de infraestrutura (construção e ampliação de ferrovias e portos). O plano foi elaborado durante o governo de Paulo Hartung no ano de 2006, através da Secretaria de Economia e Planejamento, em parceria com a ONG Espírito Santo em Ação e patrocínio da Petrobras. 
se que, principalmente a partir do ano de 2007, no momento em que a Petrobras comunica a descoberta do pré-sal, houve uma intensificação na abertura de novos nichos de investimentos no estado, ao mesmo tempo em que retroalimenta a expansão de cadeias extrativas e complexos industriais já instalados no seu primeiro boom desenvolvimentista, no final da década de 1960.

O modus operandi dos grandes projetos enquadra-se em uma lógica pautada pelos interesses da arena internacional e que reafirma uma "vocação" histórica da América Latina enquanto fornecedora de matéria-prima. Milanez e Santos (2013) denominam de neoextrativismo esse quadro político-econômico, trazendo de Gudynas (2009, 2012a) a definição do termo como um modelo de desenvolvimento focado no crescimento econômico e baseado na apropriação de recursos naturais, em redes produtivas pouco diversificadas e na inserção internacional subordinada. De acordo com Svampa (2012), ingressamos em um novo padrão de acumulação de capital baseado na exportação de bens primários em grande escala - o Consenso de Commodities. A autora ainda afirma que as novas normas legais firmadas pelo Estado metarregulador garantiram a institucionalização dos direitos das grandes corporações, assim como a aceitação de normas criadas nos espaços transnacionais homogeneizaram o mapa socioprodutivo no setor de mineração, pesca, petróleo e gás, dentre outros.

Todo este processo implica na subordinação de territórios já ocupados por populações que participam de modos de vida, ou modos de atender às suas necessidades materiais de subsistência e de constituição simbólica, com pouca inserção no mercado capitalista. São comunidades pesqueiras, quilombolas, campesinas, indígenas e pequenos distritos urbanos, todos transformados em "zonas de sacrifício", ou seja, espaços destinados à degradação em nome do progresso do país (ACSELRAD, 2010; LERNER, 2010). Assim, os impactos ambientais e sociais resultam em um tensionamento constante e crescente que acaba por acarretar uma série de conflitos entre atores antagônicos. 
Reunidos em torno do framing de afetados ${ }^{4}$, muitos atores que estão na base dos conflitos vêm se mobilizando em um amplo leque de coletivos (rurais ou urbanos) e modalidades de resistência em defesa do meio ambiente, dos recursos naturais, da biodiversidade, além da preservação de modos de vida e usos dos territórios tradicionais. O enquadramento de "afetados", de acordo com Losekann, ocorre pela:
[...] identificação de antagonistas comuns - empresas, corporações, governos, Estados - e por explicações que convergem para a correlação entre capitalismo, globalização e desenvolvimento baseado no extrativismo - ou seja, mais um mecanismo cognitivo em operação (LOSEKANN, 2016, p. 142).

Compreende-se que as dinâmicas territoriais, verificadas a partir do processo de visibilização de uma luta local, apresentam elementos fundamentais para a realização de uma análise aprofundada sobre este tipo de ação coletiva constituída através de um sujeito "glocal" (ou broker) que, ao mesmo tempo em que está muito enraizado no território, atua em redes transnacionais em busca de um redimensionamento da condição territorial local em uma luta política que conecta territórios distintos.

Assim, o presente artigo apresenta uma investigação sistemática das dinâmicas e processos de mobilização que ocorrem em lutas que contestam especificamente a exploração de petróleo e gás na América Latina. Analiticamente, examina-se a dimensão espacial das lutas nas transposições de escalas de ação coletiva e o papel do broker nestas transposições. Para tanto, temos como base

\footnotetext{
4 Losekann (2016, p. 141) defende que "afetado" não constitui uma identidade, e que seria mais adequado "entender essa designação como um "enquadramento" e um mecanismo cognitivo que ocorre pela compatibilização de diversas identidades coletivas convergentes (ambiental, indígena, quilombola, agroecologia, gênero, pescadores etc.), em uma dada condição, e a partir de mecanismos relacionais e interativos que articulam atores diversos".
} 
a literatura do Contentious Politics, brokerage e ativismo em redes transnacionais. Nossas conclusões são de que as lutas em questão colocam um elemento não considerado na agenda do Contentious Politics, qual seja, apresentam confrontos que são de natureza ontológica, onde mundos distintos estão em disputa.

\section{Os caminhos teórico-metodológicos}

A análise apresentada é preliminar de uma pesquisa que busca compreender não estritamente os aspectos locais, mas as intermediações entre o local e o global, tendo em vista os fluxos reivindicativos de afetados por empreendimentos da indústria do petróleo e gás na América Latina. Kirsch (2014) ao analisar processos reivindicativos semelhantes, precisamente aqueles contra o empreendimento Ok Tedi mine da mineradora BHP Billiton, em Papua Nova Guiné, caracterizou como "políticas do espaço" as redes de atores que criaram contestação no local da mina e que foram alçadas para arenas internacionais, gerando um processo transnacional de confronto. Isto posto, buscamos compreender de que maneira se constituem as políticas do espaço entre as comunidades locais no Espírito Santo e outras arenas não locais.

Metodologicamente, procedemos de uma abordagem qualitativa, operacionalizada por observações de campo, pesquisa documental e entrevistas em profundidade semiestruturadas. A explicação fundamenta-se a partir de análise empírica do processo de construção da Campanha "Nem um poço a mais", que envolveu uma atenção etnográfica ao acompanhar suas performances de confronto (toxic tours, intercâmbios de afetados, seminários, oficinas, missões, eventos de formação e reuniões). A campanha articula-se em torno do framing de "afetados" e gera uma rede latino-americana empenhada em realizar diagnósticos comuns e na expansão de uma nova gramática coletiva. 
As entrevistas foram realizadas com atores que participam ativamente da Campanha e são representantes da FASE/ES 5 , uma organização não governamental que tem papel essencial no fomento às mobilizações antipetroleiras no ES, desenvolvendo ações de formação, produção de conhecimento e de incidência em políticas públicas que dão visibilidade às questões voltadas à promoção da justiça ambiental, defesa dos bens comuns e dos direitos territoriais. A ONG é uma das articuladoras da Campanha "Nem um poço a mais", com ativistas antipetroleiros e representantes de grupos e das comunidades impactadas. Além disso, articula redes de incidência e visibilidade política, estando inserida na Rede Brasileira de Justiça Ambiental (RBJA) e na Oilwatch ${ }^{6}$.

Salientamos que um dos aspectos centrais no que diz respeito às escolhas metodológicas, mas que também se relaciona com uma linha teórica em voga entre intelectuais latino-americanos, consiste em um compromisso com as histórias e modos de vida ocultados e/ou inferiorizados por uma lógica eurocentrada. Como propõe Bringel, não se trata de negar as teorias provenientes do norte, "mas uma articulação do potencial crítico destas com teorizações e experiências do Sul-Global" (BRINGEL, 2011, p. 188). Para tanto, os estudos decoloniais se fazem aliados neste trabalho.

O ponto de partida destes estudos é justamente a constatação de que toda enunciação tem um lugar de origem. Conforme Mignolo (2005) assinala, a ideia de um "hemisfério ocidental" na América

\footnotetext{
${ }^{5}$ A FASE (Federação de Órgãos para Assistência Social e Educacional) é uma ONG fundada em 1961, sem fins lucrativos, que atua em seis estados brasileiros. Desde suas origens, esteve comprometida com o trabalho de organização e desenvolvimento local, comunitário e associativo. Sua atuação se dá a nível local, nacional e internacional com vistas a integrar redes, fóruns e plataformas, sempre visando derrotar políticas de caráter neoliberal. Disponível em: https://fase.org.br/pt/quem-somos/historico/.

${ }^{6}$ Autodenomina-se rede e desenvolve estratégias globais para os afetados, atuando com a troca de informações sobre as atividades petroleiras em cada país, as práticas operacionais das companhias, além de gerar visibilidade para os movimentos de resistência e campanhas internacionais contra essas companhias. Disponível em: http://www.oilwatch.org/quienes-somos.
} 
do Sul e do Norte contribui para a consolidação de uma estrutura de poder eurocêntrico, por meio do imaginário da civilização ocidental no sistema-mundo moderno colonial. O capitalismo, assim como a modernidade, "aparece como um fenômeno europeu e não planetário, do qual todo mundo é partícipe, mas com distintas posições de poder. Isto é, a colonialidade do poder é o eixo que organizou e continua organizando a diferença colonial, a periferia como natureza" (MIGNOLO, 2005, p. 36).

$\mathrm{O}$ autor apresenta, então, o conceito de delinking, que pode ser útil para compreender o papel do broker ao conectar os diferentes espaços local e global, implicando também no contato entre o "tradicional" e o "moderno":

Um "delinking" que leva a uma mudança epistêmica decolonial e traz para o primeiro plano outras epistemologias, outros princípios de conhecimento e entendimentos e, consequentemente, outra economia, outras políticas, outras éticas. [...] Além disso, "delinking" pressupõe um movimento para uma política geo-corporal do saber que, por um lado, denuncia a pretensa universalidade de uma etnicidade particular (política do corpo), localizada em uma parte específica do planeta (geopolítica), que é a Europa, onde o capitalismo se acumulou como consequência do colonialismo. "Delinking" então deve ser entendida como uma mudança epistêmica decolonial que conduz a outra universalidade, isto é, à pluralidade como um projeto universal (MIGNOLO, 2007, p. 453, tradução nossa).

Nesse sentido, as mobilizações que contestam o extrativismo de petróleo e gás na América Latina provocam uma interação entre valores e práticas relacionados a mundos distintos em disputa. Os reflexos deste confronto de mundos produzem características que marcam a ação contestatória dos atores e de suas estratégias. Combinam-se performances antissistêmicas, desobedientes e ilegais - realizadas em nome da legitimidade das formas de ação ancestrais - com outras que são típicas do mundo moderno 
ocidental. Este aspecto é observável, principalmente, nas dinâmicas que combinam estratégias jurídicas e a crítica à juridificação. $\mathrm{Ou}$ seja, as escolhas táticas performatizam embates ontológicos entre os mundos em disputa.

Por fim, a abordagem está fundamentada na literatura de matriz norte-americana dos movimentos sociais, especificamente no Contentious Politics, que surge visando uma desvinculação do estruturalismo e em busca de interpretações mais relacionais não somente para os movimentos sociais, mas para diversas formas de contestação política e social (BRINGEL, 2011). A publicação da obra Dynamics of Contention (MCADAM; TARROW; TILLY, 2001) representa um importante marco no sentido de que o trio de autores reformulam seus próprios conceitos (repertórios, oportunidades e ameaças, enquadramentos e estruturas de mobilização) e apresentam avanços importantes, embora não tenham passado ilesos de receber duras críticas. O êxito está, sobretudo, na centralidade dada aos "mecanismos causais" enquanto unidades analíticas determinantes. Dentre eles, focaremos em um específico, o brokerage (intermediação), seguindo a definição proposta por Marisa von Bülow, como "iniciativas que conectam atores (indivíduos, organizações ou setores) que estão separados por distância geográfica, falta de confiança ou falta de recursos, ou simplesmente por não estarem cientes da existência uns dos outros" (VON BÜLOW, 2010, p. 108, tradução nossa).

Ademais, embora os aspectos macro econômicos e políticos sejam fundamentais para compreender o processo de mobilização dos afetados, um olhar diretamente para os territórios é fundamental. Mas, ao mesmo tempo, o sentido de "afetado" está para além do território, permitindo o "surgimento de uma visão da contestação enquanto algo maior do que o conflito específico entre uma comunidade e uma empresa. Trata-se de um mundo inteiro (um modo de viver) que está ameaçado" (LOSEKANN, 2016, p. 136). Isto posto, para compreender a atuação do broker (intermediário) que, no contexto apresentado, conecta vivências nos territórios afetados com os espaços externos da militância e, por conseguinte, é capaz de produzir vínculos e trocas entre 
os diferentes mundos em confrontação, a seguinte elaboração desenvolvida pela autora caracterizando os afetados em três posições distintas se faz aliada desta análise:

A primeira seria a dos afetados em si, que são os pescadores, as populações em geral e os campesinos, que não necessariamente se percebem enquanto afetados, mas sim pelo olhar de outro. [...] Podemos identificar a segunda posição como afetados mobilizados, em que encontramos os próprios sujeitos dos territórios impactados, mas que já são conscientes e mobilizados em torno dessa situação. [...] A terceira categoria seria a dos mobilizadores dos afetados, caracterizado por aqueles atores que não estão sofrendo as consequências diretas dos empreendimentos, mas que percebem a situação do afetado no outro e mobilizam-se por e com ele [...] (LOSEKANN, 2016, p. 136).

Compreende-se que o broker, enquanto mobilizador dos afetados, tem uma grande capacidade de construir significados de resolução de necessidades, de direitos, num sentido emancipatório, em suma, de alternativas societárias. Tais atores são também cruciais para as transposições escalares entre o território local e o global onde se projetam os discursos macro políticos. Isso ocorre através de um jogo que se dá entre os afetos daqueles que vivem no território e sofrem os impactos, de emoções paralisantes para emoções que motivam a ação. Não estar submetido ao sofrimento do território e suas situações de opressão, tal como os afetados em si, propicia aos atores mobilizadores um certo jogo de ambivalência em que se conhece o sofrimento, mas também se transita fora dele. É este transitar entre mundos, vivências e suas distintas afetações que caracteriza e confere importância singular ao broker nos conflitos ambientais. 


\section{A intermediação enquanto ator e enquanto performance forjada}

Desde os anos 1960 e 1970, o litoral do Espírito Santo é locus de instalação de complexos portuários e industriais associados à transformação e exportação de minério de ferro e de pasta de papel. A região, contudo, passa a sofrer desde os anos 1990, e de forma mais acentuada nos anos 2000, com o avanço de grandes projetos logísticos e portuários e/ou novos terminais dedicados à exploração e apoio à cadeia de petróleo e gás, muito em função da descoberta do pré-sal e dos preços do "ouro negro" que subiram $482 \%$ entre dezembro de 2000 e janeiro de 2013 no mercado internacional (ZANOTELLI, 2015). Ao final de 2009, já havia 11 campos de produção marítimos e os terrestres somavam 254 poços (GONÇALVES, 2011).

Ocorre que essa indústria, por se assentar em uma complexa infraestrutura (plataformas, navios, estaleiros, estradas, gasodutos e oleodutos, unidades de processamento e ajuste, etc.), é marcada por processos de espoliação de territórios e bens de uso comum. Neste contexto, em abril de 2012, no município de Linhares, realizou-se a primeira iniciativa para a construção de uma frente antipetroleira no ES, reunindo "integrantes de movimentos sociais, organizações de pescadores, quilombolas, trabalhadores terceirizados, moradores das áreas de risco, ONGs, entidades ambientalistas, pesquisadores universitários, professores, estudantes, ciclistas e artistas"7. O "I Encontro dos Afetados por Petróleo e Gás no Espírito Santo" objetivava construir uma mobilização que iniciasse um debate coletivo em busca de um outro sentido de progresso, levando em conta a narrativa dos próprios afetados. Como resultado, foi formulado o "Fórum dos Afetados por Petróleo e Gás do ES" por grupos que percebem que a chamada crise ecológica atinge de maneira diferenciada os diversos setores da sociedade, baseados em uma perspectiva de justiça ambiental.

\footnotetext{
${ }^{7}$ Fonte: Carta de Linhares (2012). Disponível em: https://areaslivresdepetroleo. wordpress.com/areas-livres-de-petroleo/pagina-6/.
} 
Outro marco importante foi o "V Encontro Nacional da Rede Brasileira de Justiça Ambiental", realizado em agosto de 2013, no município da Serra, região metropolitana do ES. O tema escolhido foi "Articulando resistências frente às injustiças ambientais do atual modelo energético", pois entendia-se que a temática possui um caráter articulador e já mobilizava distintos sujeitos que compunham a rede. $\mathrm{O}$ encontro contou, mais uma vez, com uma diversidade de atores (afetados de todo o país, organizações, movimentos sociais, ativistas, pesquisadores, artistas, etc.) e representantes das organizações Oilwatch e Acción Ecológica, do Equador, que inspiraram o que aparece na carta política do encontro como uma "radicalização" da luta por Justiça Ambiental:

Mas este encontro nos trouxe muitas inspirações, radicalizando a luta por Justiça Ambiental como a proposta, apoiada pelo povo equatoriano, de deixar o petróleo no subsolo em Yasuní na selva amazônica. Processo onde a Petrobras foi denunciada por violar direitos das comunidades e degradar os territórios, sendo assim, pressionada pela sociedade para se retirar do Equador. Rechaçamos a decisão do presidente Rafael Correa de retroceder essa conquista popular e liberar a exploração petroleira no blocos 31 e ITT no Parque Nacional de Yasuní. ${ }^{8}$

A partir da troca de experiências com os membros das redes latino-americanas, começam a surgir bandeiras "Nem um poço a mais" ou "Deixar o petróleo no subsolo" nas mobilizações locais, onde se propõe que as populações possam ter o direito de dizer não à exploração nas áreas pesqueiras, comunidades litorâneas, quilombolas, indígenas, camponesas, áreas de assentamento de reforma agrária ou de grande biodiversidade.

\footnotetext{
${ }^{8}$ Carta política do V Encontro Nacional da RBJA, 2013. Disponível em: https:// redejusticaambiental.wordpress.com/2013/09/13/declaracao-do-v-encontronacional-da-rede-brasileira-de-justica-ambiental/
} 
No contexto apresentado, a FASE/ES destaca-se como um importante ator "mobilizador dos afetados" (LOSEKANN, 2016), desempenhando o mecanismo de intermediação ao conectar os territórios no ES com circuitos da sociedade civil global, e também com outros territórios afetados no mundo, principalmente através da realização de intercâmbios.

Importante frisar que a ONG já havia participado ativamente de um forte conjunto de mobilizações em defesa das terras indígenas, quilombolas e camponesas no ES frente à empresa Aracruz Celulose e seus extensivos plantios de eucalipto. Visando ao apoio e visibilização da resistência das comunidades, constituiu-se na época a "Rede Alerta Contra o Deserto Verde", que convergiu diversas frentes de luta e encontrou nos debates sobre mudanças climáticas a possibilidade de alçar as demandas locais para espaços transnacionais, atuando conjuntamente com diversas redes, organizações e movimentos - destacando-se a $W^{2} M^{9}$ e a RECOMA ${ }^{10}$. Muitas das articulações realizadas a partir da "Rede Alerta" permaneceram no atual cenário e foram fundamentais para que se conformasse a mobilização antipetroleira no estado. Tanto a Oilwatch quanto a Acción Ecológica se conectam com a FASE/ES a partir dos espaços transnacionais de interação e das discussões climáticas, vínculos que permanece no atual contexto.

O debate sobre os conflitos e impactos em torno da expansão da indústria do pré-sal no ES passa a integrar a agenda de ações da ONG da seguinte forma:

\footnotetext{
${ }^{9}$ A World Rainforest Movement é uma organização que, desde 1986, reúne ativistas de diferentes partes do mundo em resposta à contínua destruição de florestas no Sul Global e ao consumo excessivo de produtos de madeira tropical no Norte Global.

${ }^{10}$ A Rede Latino-Americana Contra as Monoculturas de Árvores é uma rede descentralizada de organizações, criada no ano de 2003 durante o Fórum Social Mundial, com o objetivo básico de coordenar atividades a nível regional contra a expansão das plantações industriais de árvores. Ao mesmo tempo, busca apoiar alternativas social e ambientalmente sensatas, partindo de iniciativas comunitárias.
} 
Mas a partir de 2006/2007, com o evento do pré-sal e como o ES é o segundo maior produtor de petróleo, mais do que isso, o pré-sal, boa parte dele também se concentra no ES, e vendo a avalanche petroleira que estava chegando, e ainda está chegando, começamos a pensar: bem, não vale a pena ficar concentrado só no eucalipto e na celulose. [...] Então isso também nos libera como FASE para não precisar concentrar 100\% das nossas ações na luta quilombola e na luta contra a monocultura, percebendo a chegada do petróleo no estado. E aí, bem, começa um novo universo. Outros territórios, no sul do estado, na região metropolitana, na região norte também, e os próprios territórios aqui no norte, uma série de projetos petroleiros de extração de petróleo, de dutos, de instalações de gás, de portos, ferrovias, toda essa infraestrutura de chegada do petróleo já desenhada pela Petrobras, pelo governo e pelas também multinacionais do petróleo. [...] Então temos uma oportunidade histórica de atuar contra a chegada petroleira num momento em que o mundo debate sobre a substituição do petróleo e o fim dos combustíveis fósseis por causa da crise climática (Entrevista com coordenador da FASE/ES, maio de 2016).

Assim, a ONG passa a desempenhar a importante função de mobilizadora, atuando a partir da percepção social do outro, portanto, na perspectiva dos afetados em si. Além disso, promove uma série de performances de confronto: intercâmbios de afetados; toxic tours (ou "giros territoriais"); missões ou visitas periódicas para acompanhar a situação dos afetados em si; assessoria jurídica; participação em audiências públicas; panfletagens; produção de cartilhas, artigos, cartas e outros documentos denunciativos e informativos; reuniões com representantes dos poderes executivo, legislativo e judiciário. Estas atividades conectam os ativistas em um processo de interação, produzindo mudanças permanentes e reelaborações das realidades locais. 
Destaca-se que os intercâmbios de afetados são cruciais ao proporcionar um espaço de trocas entre os grupos que estão imersos em diferentes situações de "afetações", como aponta o trecho abaixo:

\begin{abstract}
Então começamos esse processo de identificação dos conflitos, [...] criar canais de intercâmbios, de troca de experiências entre os espaços que estão sendo afetados. Então, por exemplo, um porto tá chegando em Marataízes, ou lá no sul do estado, em Presidente Kennedy... Bem, já temos uma experiência de um porto petroleiro em Barra do Riacho, o povo de Barra do Riacho tem o que dizer sobre a sua experiência com o povo lá de Presidente Kennedy, onde o porto tá pra chegar. Então a troca desses intercâmbios e a conexão de experiências, e também o desejo das pessoas de se encontrarem e criarem canais coletivos de resistência, estratégias conjuntas, isso é o que tem sido um novo norte do nosso trabalho (Entrevista com coordenador da FASE/ES, maio de 2016).
\end{abstract}

Assim, os intercâmbios geram um processo de circulação de informações sobre operações das companhias petroleiras em cada localidade, suas práticas operacionais e os diferentes movimentos de resistência e campanhas internacionais contra companhias específicas. Firma-se também um compromisso com a busca do avanço da consciência ambiental a nível transnacional, preocupada em estabelecer vínculos entre a destruição da biodiversidade, com as mudanças climáticas e violações de direitos humanos. Portanto, o objetivo consiste em formar uma rede de organizações que atuem a nível local para que seja capaz de intervir em torno de um mesmo enquadramento a nível transnacional para a proteção da vida e dos meios de sobrevivência das populações, vinculando os impactos ambientais com os impactos sociais da atividade.

Por fim, podemos refletir que as "redes" são construídas nos dois sentidos: tanto pelo projeto desenvolvimentista através dos empreendimentos interligados que se instalam nos territórios 
e causam impactos às distintas territorialidades (terra e mar), quanto pela resistência e pressão confrontadora desempenhada pelos afetados e seus parceiros de luta. Isto evidencia a importância desse formato organizacional no contexto descrito ao proporcionar um espaço de interação entre sujeitos, organizações, campanhas, coletivos, movimentos sociais, etc., conectando os afetados em si com atores já engajados e mobilizados em torno de um mesmo enquadramento. Através desse entrelaçamento será constituída a mobilização propriamente dita.

Tendo em vista os elementos expostos, a experiência latinoamericana apresenta grandes possibilidades de uma desconstrução em direção a um decolonial thinking (MIGNOLO, 2007), que envolve um deslocamento de lógicas, colocando em primeiro plano assuntos negados pelo imperialismo, e inicia-se quando os sujeitos subalternizados passam a tomar consciência dos efeitos da colonialidade do ser, do corpo e do conhecimento. Um delinking envolve outras epistemologias, outros princípios de conhecimento e compreensão do mundo e, consequentemente, outras economias, outras políticas, outras éticas.

\section{A intermediação entre mundos em confronto e ampliação dos atores}

O mecanismo de intermediação também constitui uma interação entre mundos distintos. A resistência ao petróleo evoca uma ontologia ancestral e pós-civilizacional que é constitutiva deste confronto político. Isso evidencia-se na Campanha e seus vários eventos.

Em junho de 2015 ocorreu o lançamento da já consolidada Campanha "Nem um poço a mais", no município de Vila Velha, região metropolitana do ES, com o objetivo de frear a expansão petroleira sobre os territórios. A campanha constitui-se para gerar um processo de visibilização dos impactos que têm significado a expansão e aprofundamento do modelo dependente do petróleo e seus derivados, que gera uma série de consequências, muitas vezes irreversíveis, significando o sofrimento e degradação para 
uma população que historicamente tem sido penalizada. Esse configura-se como um dos elementos nucleares do conflito entre as ontologias de mundos que estão em jogo neste processo.

Ao fim do encontro é produzida uma carta política na qual uma pluralidade de organizações, coletivos, associações, conselhos, grupos organizados de afetados etc., declaram que "é hora de repensar e agir sobre a expansão petroleira e da teia de empreendimentos predadores que a alimenta", tomando a decisão de tornar pública a campanha. A carta é concluída da seguinte forma:

Estamos lançando esta campanha a partir das nossas realidades, vidas e quereres. É dos nossos territórios, onde vivenciamos toda a violência da cadeia produtiva petroleira, que se construirá a nossa luta. Afirmamos que a terra e o mar, para além dos que neles trabalham, é de quem neles vivem. Viemos a público afirmar que nossa dor e nossa luta têm dignidade. Não seremos criminalizados e hostilizados por nossa decisão. Com a sabedoria dos que preservaram desde sempre os territórios, nos declaramos aptos a zelar por eles e pelos bens naturais neles contidos. Exigimos ser considerados em nossa soberania e direito de autodeterminar nossos futuros (Carta do encontro de lançamento da Campanha "Nem um poço a mais", junho de 2015).

No mencionado encontro, participa e assina a carta política o coletivo equatoriano Yasunidos, que se autodeclara: "Somos jovens, mas também somos estudantes, artistas, trabalhadores, mães, pais, filhos, filhas e ativistas. Somos apartidários, mas não somos apolíticos. Somos ecologistas, animalistas, feministas, pró-direitos e confluímos na diversidade"11. O coletivo passa a se articular em resposta ao anúncio do então presidente equatoriano Rafael Correa de pôr fim ao projeto Yasuní-ITT, executando uma ampla

${ }^{11}$ Fonte: http://sitio.yasunidos.org/en/yasunidos/nuestros-principios.html. 
campanha internacional possibilitada por intercâmbios através da Oilwatch e Acción Ecológica. É desta forma que um de seus ativistas participa do lançamento da Campanha "Nem um poço a mais", trazendo a experiência adquirida nesse processo e compartilhando as diversas estratégias.

Desde o seu início, o Coletivo reivindica-se como um grupo com profunda demanda política de rechaço ao modelo extrativista como única forma de se produzir riquezas. Declaram ainda: "buscamos substituir o antropocentrismo e o patriarcado por relações horizontais baseadas no respeito pela natureza, aos animais e entre nós mesmos". Logo, implica que devemos considerar uma dimensão utópica que envolva o fortalecimento de valores básicos da democracia: liberdade, igualdade e solidariedade, incorporando conceitos da vida em comunidade e direitos da natureza. Cria-se, assim, uma interação que busca a abertura de espaço para novas formas de valoração ambiental e a valorização de saberes ancestrais.

Neste sentido, o Equador chama atenção ao trazer inovações legais do ponto de vista ambiental em sua nova Constituição, como a definição do Estado plurinacional, o reconhecimento dos Direitos da Natureza (Pachamama) e a promoção do estado de Bem Viver (sumak kawsay). O artigo $71^{\circ}$ da Constituição de 2008 incorpora uma definição da Natureza, ou Pachamama, ancorada nas cosmovisões de povos indígenas, sendo o "espaço onde se reproduz e se realiza a vida". Gudynas aponta que "não restringindo o conceito ocidental de ambiente, gera-se a potencialidade de romper com o programa da modernidade, na qual está a base da crise ambiental" (GUDYNAS, 2009, p. 37).

No entanto, De La Cadena (2010) ressalta que essa reconfiguração política geralmente é interpretada como o resultado de um "giro à esquerda" dos governos latino-americanos, mas o importante a se analisar é a presença dos movimentos sociais regionais de indígenas como um elemento constitutivo dessas transformações. O fato de atores políticos "não-humanos" aparecerem nos protestos sociais pode ser a evidência de um momento de ruptura política e uma indigeneidade emergente, que a autora desenvolve: 
Quero dizer, uma insurgência de forças e práticas indígenas com a capacidade de romper significativamente as formações políticas prevalecentes e reorganizar os antagonismos hegemônicos, em primeiro lugar, tornando ilegítima (e, portanto, desnaturalizando) a exclusão de práticas indígenas das instituições do Estado-nação (DE LA CADENA, 2010, p. 336, tradução nossa).

A autora pode proporcionar uma análise da prática política e de conflitos que superam a separação entre sociedade e natureza, sendo que o reconhecimento das diferentes concepções socioculturais do uso da natureza por parte de sujeitos que sustentam os modos de vida tradicionais é condição indispensável de justiça ambiental nos conflitos que envolvem estas populações. Cabe comentar que, em muitos momentos, o agenciamento da natureza mostra-se decisivo nos processos de mobilização da ação coletiva. Assim, esta disputa de mundos sugere a incorporação da própria natureza como "afetada em si", que produz agenciamentos importantes.

\section{Reescalonando a mobilização: a conexão ES - Equador por áreas livres de petróleo}

Muitos avanços já foram realizados pelos estudiosos do Contentious Politics em busca de compreender os processos de construção das coalizões transnacionais. Kirsch (2014) defende que, no caso dos riscos e danos socioambientais, a situação de conflitos é exacerbada pela política econômica neoliberal que os normaliza e naturaliza como consequências inevitáveis da modernidade, e não como fruto de uma relação contingente entre Estado, corporações e os usos do meio ambiente. $\mathrm{O}$ autor ainda expõe que muitas das campanhas operam através de redes transnacionais de ativismo que fornecem recursos internacionais a uma nova categoria de atores, resultam em uma forma de mobilização caracterizada como "políticas de escala" e são reconhecidas como movimentos contra-globalização devido ao uso inovador da arquitetura da globalização ao desafiar as corporações. 
Observa-se que há um intenso fluxo reivindicativo de ativistas que circulam pelos diversos territórios nos quais as lutas excederam a escala local. As interações que ocorrem são imprescindíveis para que a mobilização em termos de luta propriamente dita ocorra, ao gerar um processo de reelaboração em que se vincula as queixas locais às pautas mais gerais (riscos climáticos ou crises ambientais, econômicas, civilizatórias) e se mapeia conjuntamente os canais de denúncia e estratégias de atuação possíveis baseadas em experiências de ganhos ou perdas dos grupos ali conectados, proporcionado, assim, formas de se alcançar conquistas efetivas para as diversas lutas locais.

Afirma-se, portanto, que os atores envolvidos na Campanha "Nem um poço a mais" atuam em perspectiva escalar e, neste sentido, são inspirados pelo processo em curso de mobilização no Equador em torno da preservação do Parque Nacional de Yasuní, território com grande biodiversidade e onde estão localizadas comunidades indígenas em isolamento voluntário. Através dos intercâmbios, atores da FASE/ES e das organizações envolvidas na defesa de Yasuní (Oilwatch, Acción Ecológica e Yasunidos) passaram a compartilhar experiências de enfrentamento da causa antipetroleira.

O projeto Yasuní-ITT foi apresentado pelo governo equatoriano em 2007, durante Assembleia Geral da ONU, e consistiu na promessa de suspender a atividade petrolífera na região, recebendo, por isso, recursos dos países industrializados como compensação pela não emissão de Gases de Efeito Estufa (GEE), preservação da biodiversidade e proteção aos direitos de povos indígenas. Milanez e Santos (2016, p. 50) apontam que as ONGs tiveram um papel relevante na formulação e divulgação internacional da iniciativa, sendo que a Acción Ecológica foi uma das responsáveis pela concepção e formalização "e sua posição dentro da Oilwatch contribuiu para facilitar a difusão internacional da proposta".

Nessa ampla onda de mobilizações, buscava-se não apenas impedir a exploração na região, mas levar adiante a sugestão de um mundo alternativo pela via da não exploração como forma 
legítima de preservar aquilo que é patrimônio de todos, implicando em uma mudança nos padrões de produção e consumo. Desta forma, as reivindicações pós-extrativistas passam a ocupar uma importante posição de confronto político na atual conjuntura da América Latina.

\section{Considerações finais}

Este artigo propôs-se a discutir questões iniciais e relevantes de uma pesquisa que visa compreender os fluxos reivindicativos de afetados por empreendimentos vinculados à indústria do petróleo e gás. Demonstrou-se que diferentes valorações e práticas estão envolvidas no processo de mobilização, ocasionando um "choque de mundos", e como seus reflexos produzem características que marcam a ação contestatória dos atores e suas estratégias. Nesse sentido, os intercâmbios de afetados, sendo a materialização de uma performance constituída através de um ator "glocal", ou broker, irão forjar uma vivência que vincula demandas locais com enquadramentos de projeção global. Através da atuação deste ator que circula por diferentes escalas, o que também está sendo intermediado são diferentes mundos, ou seja, pontos de vista diversos. O conflito apresentado, portanto, envolve elementos que são ontologicamente diferentes e conflitantes e o que o brokerage faz, além de promover a ação coletiva, é colocar em tensão e relação esses diferentes pontos de vista.

A Campanha "Nem um poço a mais" surge com a proposta de iniciar um debate com dimensões utópicas por áreas livres de petróleo, defendendo que as populações possam ter o direito de dizer não à exploração em seus territórios. Em suma, há um confronto civilizacional no qual questionam-se as noções de desenvolvimento e crescimento econômico pautadas por visões ocidentais e valoriza-se o conhecimento ancestral das populações tradicionais e indígenas. 


\section{Referências}

ACSELRAD, H. Ambientalização das lutas sociais o caso do movimento por justiça ambiental. Estudos Avançados, 24(68), 2010.

BRINGEL, B. Ativismo transnacional, o estudo dos movimentos sociais e as novas geografias pós-coloniais. Estudos de Sociologia (Recife), v. 16, p. 185-215, 2011.

DE LA CADENA, M. Indigenous cosmopolitics in the Andes: conceptual reflections beyond 'politics'. Cultural Anthropology, 25 (2): 334-370. 2010.

GONÇALVES, F. P. Atividade energética e riscos no litoral de Linhares: problemas e perspectivas para a gestão do território (2011). Dissertação (Mestrado em Geografia - Programa de PósGraduação da Universidade Federal do Espírito Santo), Vitória, 2011.

GUDYNAS, E. Estado compensador y nuevos extractivismos. Nueva Sociedad, v.237, p.128-146. 2012a.

GUDYNAS, E. La ecología política del giro biocéntrico en la nueva Constituición de Ecuador. Revista de Estudios Sociales No 32. p. 34-46. 2009.

KIRSCH, S. Mining Capitalism. The Relationship between Corporations and Their Critics. University of California Press. 2014.

LERNER, S. Sacrifice zones: the front lines of toxic chemical exposure in the United States. Cambridge: The MIT Press, 2010.

LOSEKANN, C. A política dos afetados pelo extrativismo na América Latina. Revista Brasileira de Ciência Política, p. 121-164, 2016.

MCADAM, D; TARROW, S; TILLY, C. Dynamics of Contention. Cambridge: Cambridge University Press, 2001. 
MIGNOLO, W. D. A colonialidade de cabo a rabo: o hemisfério ocidental no horizonte conceitual da modernidade. In: LANDER, E. (Org.). A colonialidade do saber: eurocentrismo e ciências sociais. Perspectivas latinoamericanas. Ciudad Autónoma de Buenos Aires, Argentina: CLACSO, 2005.

MIGNOLO, W. D. (2007) 'DELINKING', Cultural Studies, 21:2, 449 - 514.

MILANEZ, B; SANTOS, R. S. P. Neoextrativismo no Brasil? Uma análise da proposta do novo marco legal da mineração. Revista Pós Ciências Sociais, v. 10, n. 19, 2013.

MILANEZ, B.; SANTOS, R. S. P. A Iniciativa Yasuní-ITT: uma análise a partir do Modelo de Fluxos Múltiplos. Revista de Sociologia e Política (Online), v. 24, p. 39-65, 2016.

SVAMPA, M. Consenso de los commodities, giro ecoterritorial y pensamiento crítico en América Latina. Revista del Observatorio Social de la América Latina, Buenos Aires, ano XVIII, n. 32, p. 15$38,2012$.

VON BÜLOW, M. Building Transnational Networks: civil society and the politics of trade in the Americas. New York: Cambridge University Press, 2010.

ZANOTELLI, C. L. Cadeia do petróleo e impacto na Região Metropolitana de Vitória. In: Caderno de debates 3: Cidades, indústrias e os impactos do desenvolvimento brasileiro. Organização: Joana Barros, Evanildo Barbosa e Lívia Duarte. Rio de Janeiro: Fase, 2015, p. 59-74. 